\title{
The aplication of cyanoacrilate surgical glue on skin suture in rats ${ }^{1}$
}

João Ilgenfritz Neto', Ricardo Dutra Aydos", landara Schettert Silva'", Rondon Tosta Ramalho'v , João Ilgenfritz Júniorv, Gerson Gattats Orro de Campos ${ }^{\vee \prime}$, Ricardo Kenithi Nakamuravı, Danilo M. Zanello Guerisoliv"I, Wilson de Barros Cantero ${ }^{\mathrm{VIII}}$

'Fellow PhD degree, Postgraduate Program in Health and Development, Universidade Federal do Mato Grosso do Sul (UFMS), Campo Grande-MS, Brazil. Analysis and interpretation of data, manuscript writing.

"PhD, Associate Professor, Department of Surgery, UFMS, Campo Grande-MS, Brazil. Guid-ance and experimental design.

I'PhD, Associate Professor, Department of Surgery, UFMS, Campo Grande-MS, Brazil. Tech-nical procedures.

vPhD, Postgraduate Program in Health and Development, UFMS, Campo Grande-MS, Brazil. Technical procedures.

${ }^{\vee} \mathrm{MD}$, Universidade Federal do Rio Grande do Sul (UFRS), Porto Alegre-RS, Brazil. Analysis and interpretation of data, technical procedures, manuscript writing.

VIMD, UFMS, Campo Grande-MS, Brazil. Anesthesia procedures.

VIIPhD, Associate Professor, UFMS, Campo Grande-MS, Brazil. Statistical analysis.

VIIIPhD, Associate Professor, Department of Surgery, UFMS, Campo Grande-MS, Brazil. Critical revision, supervision all phases of the study.

\section{Abstract}

Purpose: To compare the use of a new cyanoacrylate-based surgical glue and suture with separate points in skin wounds closure.

Methods: Thirty-six rats were subjected to a $4 \mathrm{~cm}$ dorsal longitudinal incision. Twelve were subjected to simple suture with polyamide 6-0, 12 rats underwent wall synthesis using Dermabond ${ }^{\circledR}$ and 12 was performed cutaneous synthesis with N-2-Butyl-Cyanoacrylate. Twelve of each group was euthanized on the seventh postoperative day, their blood was taken to biochemical tests and a layer of skin and subcutaneous tissue surrounding the surgical scar was randomly divided in two segments, to the submission of tension tests and to histological study.

Results: There were no significant difference between groups ( $>>0.05)$. In the soft dermis there was more type I collagen production in group I $(p<0.05)$, group II and III was similar re-sults ( $p>0.05)$. In the compact dermis, all 3 groups showed similar results $(p>0.05)$. The biomechanical study was similarity between the glue groups ( $p>0.05)$ but the group III proved to be different from the others having a higher resistance ( $p>0.05)$.

Conclusion: This glue does not cause any inflammation or kidney and hepatic toxicity. Polyamide sutures are more resistant and the glue should be used alone only in less tension are-as.

Key words: Collagen. Wound Healing. Cyanoacrylates. Rats. 


\section{- Introduction}

The healing process is a sophisticated mechanism that depends on some factors and they all must be in harmony so the process can develop properly and without complica-tions. It is divided didactically in three phases but they are overlaped and progress con-tinuosly, each one of them being critical to the wound healing success ${ }^{1}$.

Cyanoacrylates were discovered in 1949 by Ardis and, about ten years later, they had their use documented in surgical procedures. They are liquid monomers that when come in contact with liquids or basic substances become strong glue that is similar to traditional methods of suture when in touch with skin².

During its development, it was observed that despite the strong sealing process, they produced an intense and long-lasting inflammatory reaction. By increasig the size of the chain molecule, these reactions reduced and increased the glue effectiveness ${ }^{3}$.

In tissue healing process, particularly in inflammatory stage, a suture should cause a minimal inflammatory reaction and limited local duration. Nonabsorbable sutures may remain longer in the surgical site causing chronic inflammation and higher chances of infecitions ${ }^{4}$.

Wound closure techniques researches substancialy evolved in the last few years, leading to several studies involving synthetic and absorbable sutures, use of staplers, tapes and others methods. The appearence of surgical glue fits in new methods of wound closure and they have been studied for about four decades ${ }^{5}$.

Surgical glue, besides being an alternative to conventional sutures, have some ad-vantages like technical easiness, decreases surgical time and, since it is not necessary the introduction of a strange substance in the body, decreases wound recovery time. These compounds have been used as complement to conventional sutures. There are studies that show that they are able to create syntheses with no suture in intestines since they do not cause tissue ischemia ${ }^{6,7}$.

They have unique properties including bacteriostatic effect, hemostatic, it's biodegradable and biocompatible, exept for methylcyanoacrilate. They are easily manipula-ble but show some drawbacks such as lower resistence in high tension areas when compared with conventional sutures and toxicity in some patients, one of the most rele-vant advantages is the surgical time reduction and the easy handling compared to oth-ers methods of synthesis ${ }^{8}$.

2-octylcyanoacrylate became available on the market in German, since then, several studies show that when this glue is used properly, the comestic result is similar or ob-ove the conventional sutures, with similar rates of infection and dehiscense. 2-octylcyanoacrylate is a glue which creates a layer over the wound keeping the the edg-es together allowing the healing process. It can be used to replace sutures with 5-0 strands or smaller in incisional wounds or lacerations, besides being waterproof ${ }^{9}$.

Although studies demonstrate many benefits, the use of cyanoacrylate glue is not fea-sible in medical practice due to its high cost. The purpose of this study was to evaluate a new surgical glue composed of $\mathrm{N}-2$ butylcyanocrylate produced by Universidade Federal do Mato Grosso do Sul (UFMS) chemical laboratory in cooperation agreement with private company under protocol number 23104.001269 / 2010-21 -UFMS by whom this glue is produced with a significan lower cost than those already on the market.

\section{- Methods}

This research project was evaluated by an ethics committee in the use of animals 
(CEUA) of the UFMS and all procedures were performed according to the Animal Ex-perimentation Ethics Committee under protocol number 520/2013, fulfilling the federal law number 11.794, of October 8, 2008 and the decree number 6.689, of July 15, 2009 which regulates the law number 11.794.

Thirty six adult, male rats were used (Rattus novergicus albinus), weighing between $250 \mathrm{~g}$ and $350 \mathrm{~g}$, coming from UFMS, animal colony.

The animals were identified by tail paint using a combination of three colors, blue, black and green, and separated in three groups of 12 animals each. They were housed in appropriate polypropylene boxes adequate for the species with size of $50 \times 40 \mathrm{~cm}$, lin-ing of wood shavings. They were randomly assigned into three groups:

GI - Containing 12 animals which were shaved and had a $4 \mathrm{~cm}$ skin incision in the back followed by cutaneous synthesis using an glue avilable in the market composed of 2-octylcyanoacrylate (Dermabond);

GII-Containing 12 animals which were shaved and had a $4 \mathrm{~cm}$ skin incision in the back followed by cutaneous synthesis using an glue composed of $\mathrm{N}$-2-butylcyanoacrylate;

GIII - Containing 12 animals were shaved and had a $4 \mathrm{~cm}$ skin incision in the back fol-lowed by cutaneous synthesis using simple suture with polyamide 6-0.

\section{Procedures}

Before the begining of the operative procedures in the surgical technique laboratory of UFMS, the animals were isolated in polypropylene boxes attached to the operating room for a period of 3 hours, aiming to reduce de preoperative stress.

For the anesthetic induction the animals were weighted on a precision digital scale and anesthetized with intraperitoneal injection with a solution of 2:1 of ket-amine hydrochloride $50 \mathrm{mg} / \mathrm{ml}$ and xylazine $20 \mathrm{mg} /$ $\mathrm{ml}$, respectively, at a dose of $(0.1 / 100 \mathrm{~g})$

Their back hair was cut with scissors followed by mechanical cleaning with soft brush soaked in polyvinyl pyrrolidone iodine $1 \%$ and rinse with sodium chloride solution $0.9 \%$.

With animals positioned on operating table in prone position, the back antisepsis was performed with iodine alcohol $2 \%$ and sterile surgical cloths were placed isolating the shaved área.

A $4 \mathrm{~cm}$ incision was made in the skin and subcutaneous tissue of the back in all groups with a 15-scalpel blade, using as references the last rib to caudal margin and spine to dorsal margin, hemostasis was done by compression.

In group I, the defect was restored using 2-octylcyanoacrylate. The group's II de-fect was restored using N-2-Butylcyanoacrylate, the edges was approximated and the synthesis made with the surgical glue produced in UFMS, placed on the inner surface of the edges. In group III, the defect was restored using suture with simple stitches with 6-0 polyamide serving as a control group. After the proce-dures the animals were returned to the same cages used in preoperative, ex-posed to incandescent light until the anesthetic recovery and manteined with food at will.

After a seven-day observation period (groups GI, GII and GIII) the animals were euthanized by increasing the anesthesia.

Then each rat was immobilized on the operating table, the mechanical suture was removed in group I, in other groups there was no need because the synthe-sis was made with surgical glue. A segment of skin and subcutaneous tissue of approximately $5 \times 3 \mathrm{~cm}$ was removed and divided into cranial and caudal parts. 
One half was directly taken to a freezer at $-20^{\circ} \mathrm{C}$ to be subjected to the study of rupture strength and the other half was immediately fixed in $10 \%$ buffered forma-lin for the histological analysis ${ }^{8}$.

The samples for rupture strength study were taken frozen for submission to the tensile strength test in the mechanical testing laboratory (National Service of Industrial Learning - SENAI, Teresina - PI, Brazil), using the testing machine DL 20000 (EMIC - Equipment and test systems Ltda, Brazil, Calibrated in 5.22.13 with certificate number 463/13) with manually adjustable gripping claws and electronic data acquisition system, Tesc software version 3.04. The wound line segments were attached to the aluminum claws lined parallel to the synthesis line and the claws were connected to the machine that performed the tension force perpendicular to the synthesis line. The result numbers were provided in kilogram force and converted to gram force. The rupture strength number corre-sponds to the highest value of the tensile force during the test, in other words, the highest tensile force to break the synthesis line. The traction occured in a $50 \mathrm{~mm} / \mathrm{min}$ speed and the tensile strength was automatically and constantly measured.

The criteria used for the microscopic study was the quantitative assessment of existing collagen in the skin synthesis observed through the picrosirius red col-oration, as well as the classification of maturation (type I and type III). It was used a microscope of Zeizz brand with a $\times 40$ magnification and a microcomputer with Proc_image program to quantify the collagen in percentage based on the princi-ples of spectrophotometry. The values reflected a ratio of the amount of collagen in a maximum of 100 points ${ }^{11}$.

For the analysis of biochemical parameters of the cyanoacrylate, it was collected after 7 days $10 \mathrm{ml}$ of blood from each animal by direct punction into the cava vein. The laboratorial exams were performed in each animal, measuring liver enzymes, aspartate and alanine aminotransferase (ASAT, ALAT), urea and cre-atinine. For analysis of the inflammatory response was laboratory dosed C-reactive protein (CRP) and serum production of interleukin-6 (IL-6). All tests were performed with quality control of the Brazilian Society of Clinical Analyses (SABC) and American Society of Pathology (SAP).

For the statistical analysis was performed a descriptive analysis of the results found for the serum values of urea, creatinine, ASAT, ALAT, C-reactive protein and interleukin- 6 as well as the analysis by Kruskall-Wallis and Brown-Forsythe, in order to compare all 3 groups (Suture with polyamide and synthesis with Dermabond $^{\circledR}$ and N-Butyl 2-Cyanoacrylate).

A descriptive analysis was performed to demonstrate the amount of collagen types I and III found in the experiment. Statistical analysis was performed using 2-way ANOVA test, complemented by Tukey's test.

For the analysis and comparison of the tensile strength found in each group was applied the Tukey's test for multiple comparisons.

\section{- Results}

One of the 36 rats used on the experimente died on the first 24 hours after the procedure, it was therefore excluded from the analysis of the criteria evaluated after 7 days. In the control group animals there were not suture dehiscence ob-served. In the animals of group I, were observed an amount of $33.3 \%$ of dehis-cence and the group II presented $41.6 \%$ of dehiscence.

The Table 1 shows the results of the descriptive analysis of the parameters studied in each group. 
Table 1 - Results found for serum urea (BUN), creatinine, ASAT, ALAT, CPR, IL-6 and rupture strengh after 7 days of the cuteneous synthesis. Expressed as mean and standard de-viation.

\begin{tabular}{lccc}
\hline & \multicolumn{3}{c}{ Groups } \\
\hline & Group I & Group II & Group III \\
\hline BUN $(\mathrm{mg} / \mathrm{dL})$ & $48.3 \pm 7.8^{*}$ & $47.8 \pm 2.9^{*}$ & $48.6 \pm 2.7^{*}$ \\
\hline Creatinine (mg/dL) & $0.39 \pm 0.03^{*}$ & $0.38 \pm 0.04^{*}$ & $0.39 \pm 0.03^{*}$ \\
\hline ASAT (U/L) & $127.2 \pm 35.9^{*}$ & $145.1 \pm 31.3^{*}$ & $170.4 \pm 72.2^{*}$ \\
\hline ALAT (U/L) & $50.67 \pm 8.5^{*}$ & $54.27 \pm 5.7^{*}$ & $53.42 \pm 5.7^{*}$ \\
\hline CPR (mg/dL) & $0.20 \pm 0.15^{*}$ & $0.19 \pm 0.18^{*}$ & $0.18 \pm 0.11^{*}$ \\
\hline IL-6 (pg/mL) & $1.51 \pm 0.03^{*}$ & $1.51 \pm 0.03^{*}$ & $1.51 \pm 0.03^{*}$ \\
\hline Rupture Strengh $(\mathrm{g})^{* *}$ & $849.6 \pm 403.3^{*}$ & $799.4 \pm 303.4^{*}$ & $1508.1 \pm 353.6^{* *}$ \\
\hline${ }^{*} \mathrm{p}>0.05 ;{ }^{*} \mathrm{p}<0.05$ & & &
\end{tabular}

The normality test indicated a gaussian distribution of data, respecting the homoscedas-ticity between the groups, reason why variance analysis was chosen. Significant diferences was found between the experimental groups $(p<0.001)$, reason why was ap-plied the Tukey's test for multiple comparisons.

The additional test showed statistical similarities between groups I and II ( $p>0.05)$. How-ever, group III proved to be different from the others $(p<0.001)$.

Table 2 - Average amount of collagen type I and III (in percent) found in the dermis of the tested animals. Expressed as mean and standard deviation.

\begin{tabular}{lccc} 
Collagen & GI (\%) & GII (\%) & Control (\%) \\
\hline Type I* & $88.6 \pm 3$ & $87.7 \pm 2.15$ & $89.5 \pm 2.05$ \\
\hline Type III** & $11.4 \pm 3$ & $12.3 \pm 2.15$ & $10.5 \pm 2.05$ \\
\hline${ }^{*} p>0.01 ;{ }^{*} p>0.01$ & &
\end{tabular}

The result of statistical analysis (2-way ANOVA complemented by Tukey's test) indicates that, in the loose dermis, the group II promoted more formation of type I collagen than other groups $(p<0.01)$, that showed similar results (Table 3$)$.

Table 3 - Average amount of type I collagen in loose and compact dermis (percent-age) found in the dermis of the animals tested. Expressed as mean and standard deviation.

\begin{tabular}{lccc} 
Dermis & GI $(\%)$ & GII (\%) & Control (\%) \\
\hline Loose & $90.2 \pm 1.6^{*}$ & $87.4 \pm 1 .^{* *}$ & $87.6 \pm 0.9^{* *}$ \\
\hline Compact & $87.0 \pm 2.8^{* *}$ & $88.0 \pm 3.1^{* *}$ & $91.4 \pm 1.6^{*}$ \\
\hline
\end{tabular}

${ }^{*} p<0.01 ; * * p>0.01$ 
In the compact dermis, using the same statistical tests, group III had more type I collagen formation $(p<0.001)$, with the other 2 groups presenting similar results ( $p>0.49)$.

When compared only the types of collagen between all the groups, there was no differ-ence when compared type I and III alone, prevailing a greater amount of type I collagen (Figures 1 to 3).

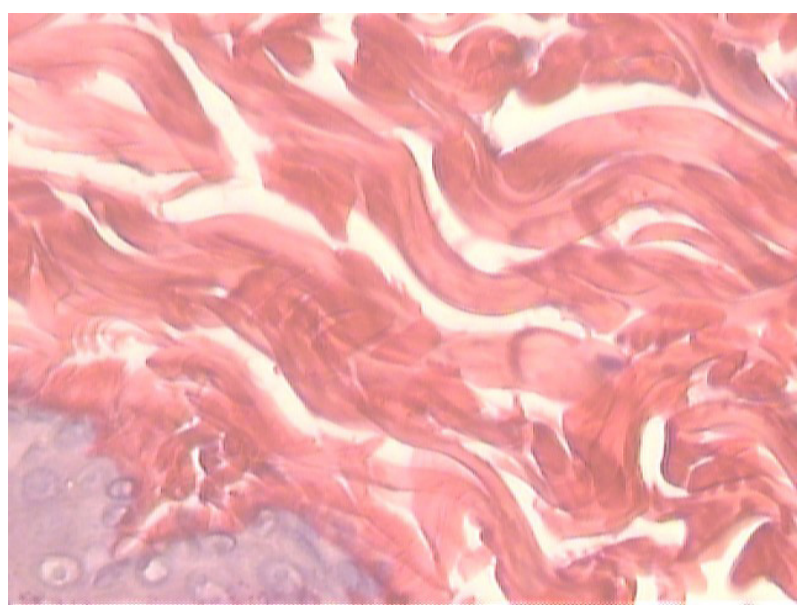

Figure 1 - Dermis photomicrograh showing thick collagen fibers stained by Picrosirius Red colour Group I.

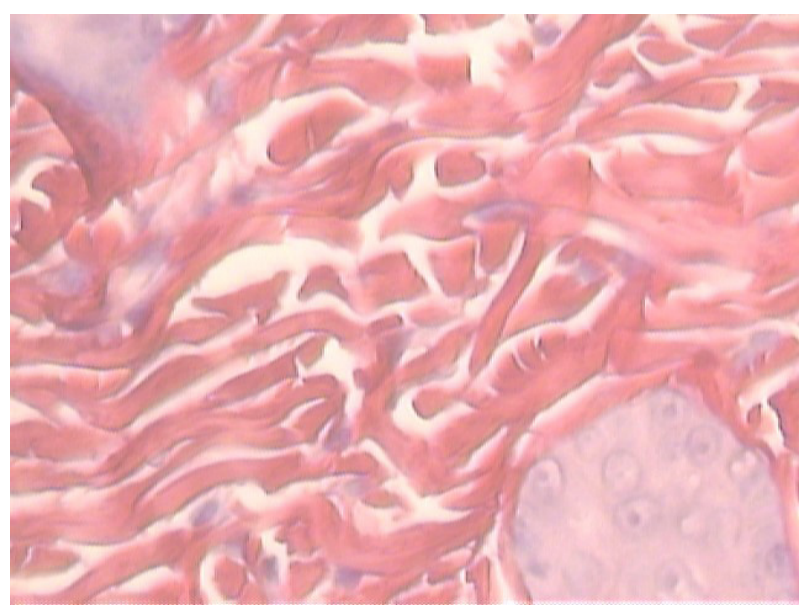

Figure 2 - Dermis photomicrograh showing thick collagen fibers stained by Picrosirius Red colour Group II.

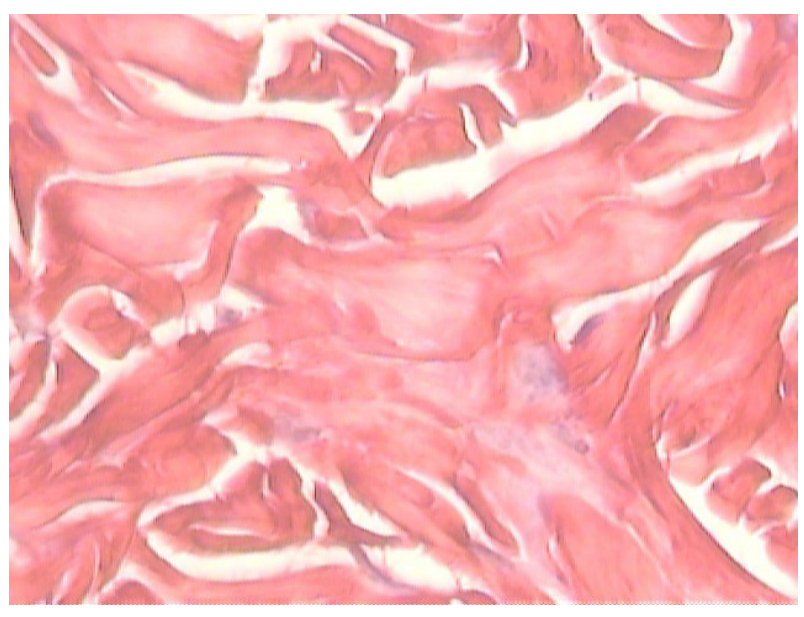

Figure 3 - Dermis photomicrograh showing thick collagen fibers stained by Picrosirius Red colour Group III.

\section{- Discussion}

In this experiment was observed that there was no alteration in the inflammatory tests analyzed in the $\mathrm{N}$-2-butylcyanoacrylate group, showing no systemic inflammatory reaction with the new glue. The values of the tests in the 2-octylcyanoacrylate and control groups with polyamide 6-0 suture also remained at the lower limit. The patterns of CRP and IL- 6 were mainteined at the device's minimum reading value, demonstrating no significant difference between the three groups $(p=0.963$ and $p=0.997$, respectively).

The inflammatory process that may be caused by the toxic products released after the detachment of the cyanoacrylate triggers the release of numerous proteins that can ac-cuse a harmful event when studied and quantified in blood. These markers are pointed as early markers of inflammatory process. The $C$ reactive protein (CRP), an acute phase reactant produced by the liver, has been used in clinical practice with an important sci-entific support ${ }^{12}$.

There was no alteration in the renal function when evaluating serum urea levels 
$(p=0.613)$ and creatinine $(p=0.704)$, showing no renal disfunction according to the normal parameters reported for this especies (45.2 $\mathrm{mg} / \mathrm{dL}-55.0 \mathrm{mg} / \mathrm{dL})(0.3 \mathrm{mg} / \mathrm{dL}-1$ $\mathrm{mg} / \mathrm{dL})$, respectively. The kidney is a vital organ with fundamental importance in body homeostasis, receiving approximately $25 \%$ of cardiac output. The renal disease is de-fined as the occurence of renal morphological lesions or biomechanical abnormality related to the renal function ${ }^{12,18}$.

The short chain cyanoacrylates stimulate severe inflammatory reaction. The Methyl-2-Cyanoacrylate has necrotizing and pyogenic properties when applied on liver surface, subcutaneous tissue, muscle and bone marrow. Coon et al. ${ }^{13}$ demonstrated the development of chronic inflammatory alterations in hearts and kidneys of rats exposed to formaldehyde ${ }^{13}$.

Analyzing the liver enzymes, two animals from group I, six from group II and four from group III had results slightly above the physiological parameters of ASAT (152.4 \pm $6.6 \mathrm{mg} / \mathrm{dL}$ ) and no animal got abdnormal ALAT values after 7 days for the species $(61.0 \pm 2.4$ $\mathrm{mg} / \mathrm{dL}$ ), showing that the glue did not cause liver damage ${ }^{18}$.

In wound healing, after $48 \mathrm{~h}$ of the injury, stands out a fibroplasia phase characteryzed by an intense fibroblast invasion and multiplication, and healing tissue proteins pro-duction and proliferation. The first collagen fibers appear with 4 or 5 days from a fundamental substance produced by fibroblasts (amorphous-mucopolysaccharides) which, in addition to produce these fibers, also guides them. The use of picrosiuris red staining was extremely relevant in order to measure the amount and type of collagen fibers, if young or mature, coloring the protein fibers with green when young and red when ma-ture (Type I and III respectively) ${ }^{14}$.

After 7 days of experiment was demonstrated that, the three groups presented a higher amount of type I collagen in comparison to type III, in loose and compact dermis, reflect-ing a wound with greater amount of mature and resistente collagen.

Type I collagen is the most common, synthesized by fibroblasts and is most predominant in bones and tendons. Type III collagen is commoly found in blood vessels, dermis and fascia. Healthy dermis contains about $80 \%$ of collagen and $20 \%$ of type $1 \mathrm{II}^{15}$.

When compared the three groups only in relation to type I collagen, in this study, the 2-way ANOVA test complemented by Tukey's test, showed that group I promoted a higher formation of mature or type I collagen than other methods of synthesis $(p<0.01)$, which showed a similar result $(p=0.97)$. In compact dermis using the same statistical methods we had a higher formation of type I collagen in control group $(p<0.01)$. With the other two groups presenting similar results $(p>0.49)$.

It was observed, in this study, a similar rate of short-term dehiscence to literature, show-ing that this glue is less efficient in hightension areas than conventional suture, restricting its aplication to less tension areas.

Despite the many advantages documented by de CA glue, its use remains restricted, due its limited effect in high-tension areas. Using Cavia Porcellus species, Noordzij et al.16 found significant defferences in wound tension immediately after the repair. The authors also concluded that the suture group had a tensile strengh 12 times greater than the glue group, but after 7 days, there were no more differences in the tensil strengh.

Analyzing animals tensile strengh of the cutaneous synthesis, the Tukey's test showed in both groups I and II signifcantly weaker wounds after 7 days of observation when compared to the suture group $(p<0.001)$. When comparing both groups submited to cu-taneus synthesis with the surgical CA glue, there was no significant differences be-tween the tensile strengh ( $p>0.05$ ). Previous studies suggest the simultaneous use of porous tapes to help the coaptation of the wound edges and enhance 
the synthesis ${ }^{2,17}$. By analyzing our study and previous authors, it can be concluded that this glue should not be used alone in high-tension areas.

The CA glue use should be limited to non-contaminated or infected wounds, lowtension areas, traumatic or surgical wounds since there is no dificulty in coaptating the wound edges. In fragile skin areas, it has advantages over the suture because it does not cause injury or tissue ischemia ${ }^{2}$.

\section{Conclusion}

This glue does not cause any inflammation or kidney and hepatic toxicity. Polyamide sutures are more resistant and the glue should be used alone only in less tension are-as.

\section{References}

1. Janis JE, Harrison, B. Wound healing: part I. Basic science. Plast Reconstr Surg. 2014 Feb;133(2):199e-207e. doi: 10.1097/01. prs.0000437224.02985.f9

2. Oliveira CL, Santos CHM, Bezerra, FMM, Bezerra MM, Rodrigues LL. Utilização de adesivos de cianoacrilato em suturas de pele. Rev Bras Cir Plast. 2010;25(3):573-6. doi: 10.1590/S1983-51752010000300030.

3. Toriumi DM, Chung VK, Capelle QM. Surgical adhesives in facial plastic surgery. Otolaryngol Clin North Am 2016 Jun;49(3) 585-9. doi: 10.1016/j.otc.2016.02.

4. Bernis-Filho WO, Wouters F, Wouters $A A B$, Bernis VMO, Lopes LR, Andreollo NA. Estudo comparativo entre fios de algodão, poligalactina e poliglecaprone nas anastomoses intestinais de cães. Arq Bras Cir Dig. 2013;26(1):18-26. doi: 10.1590/S010267202013000100005 .

5. Schivamurthy DM, Singh S, Reddy S. Comparison of Octyl-2-cyanoacrylate and conventional sutures in facial skin closure. Natl J Maxilofacial Surg. 2010;1(1)15-19. doi: 10.4103/0975-5950.69151.

6. Nose SN, Sasaki T, Saka R, Minagawa K,
Okuyama H. A Sutureless technique using cyanoacrylate adhesives when creating a stoma for extremely low birth weight infants. Springerplus. 2016 Feb;5:189. doi: 10.1186/ s40064-016-1852-y.

7. Faion $A G$, Filho $A D$, Alcantara TM, Ferreira TSA. O Etil-2-cianoacrilato como selante após ressecção parcial do ceco em Rattus Norvegicus albinus. Rev Col Bras Cir. 2011;38:45-53. doi: 10.1590/S010069912011000100009.

8. Lins RDAU; Gomes RCB, Santos KSA, Silva PV, Silva RTM, Ramos IA. Use of cyanoacrylate in the coaptation of edges of surgical wounds. An Bras Dermatol. 2012;87(6):871-6. doi: 10.1590/S0365-05962012000600008.

9. Lee HE, Min SH, Kim KMK. Analysis of Octyl2-Cyanoacrylate as a dressing ma-terial after pediatric urological procedures. J Korean Soc Pediatr Nephrol. 2013;16:115-20. doi: 10.3339/jkspn.2012.16.2.115.

10. Tognini JRF, Neves D, Souza A, Aydos RD. Efeito da conservação por formas de congelamento na avaliação da força de rotura de cicatrizes da parede abdominal de ratos. Acta Cir Bras. 1994;13(4):256-9. doi: 10.1590/S0102-86501998000400010.

11. Tognini JRF, Fagundes DJ, Novo NF, Juliano Y. Estudo biomecânico e morfológico da cicatrização da parede abdominal sob ação do meloxican. Acta Cir Bras. 2000;15(3). doi: 10.1590/S0102-86502000000300003.

12. Gomes MAM, Macedo Neto NC, Bispo IGA. Interleucina-6, moléculas de adesão intercelular-1 e microalbuminúria na avaliação da lesão endotelial: revisão de literatura. SOCERJ. 2009;22(6):398-403.

13. Coon RA, Jones RA, Jekins Jr L, Siegel J. Animal inhalation studies on ammo-nia, ethylene glycol, formaldehyde, dimethylamine, and ethanol. Toxicol Appl Pharmacol. 1970 May;16(3):646-55. PMID: 4987187.

14. Fontes CER, Taha MO, Fagundes DJ, Ferreira MV, Prado Filho OR, Mardegan MJ. Estudo comparativo do uso de cola de fibrina e cianoacrilato em ferimento de fígado de rato. Acta Cir Bras. 2004;19(1):37-42. doi: 10.1590/S0102-86502004000100006.

15. Balbino CA, Pereira LM, Curi R. Mecanismos 
envolvidos na cicatrização: uma revisão. Rev Bras Cienc Farm. 2005;41(1):27-51. doi: 10.1590/S1516-93322005000100004.

16. Noordzij JP, Foresman PA, Rodeheaver GT, Quinn JV Edlich RF. Tissue adhe-sive wound repair revisited. J Emerg Med. 1994;12(5):645-9. PMID: 7989692.

17. Singer AJ, Quinn JV, Hollander JE. The cyanoacrylate topical skin adesives. Am
J Emerg Med. 2008;26(4):490-6. doi: 10.1016/j.ajem.2007.05.015.

18. Branco ACSC, Diniz MFM, Almeida RN, Santos HB, Oliveira KM, Ramalho JA, Dantas JG. Parâmetros bioquímicos e hematológicos de ratos Wistar e camun-dongos Swiss do Biotério Professor Thomas George. Rev Bras Ciênc Saúde. 2011;15(2):209-14. doi: 10.4034/RBCS.2011.15.02.11.

\section{Correspondence:}

Ricardo Dutra Aydos

Avenida Senador Felinto Muller, s/n 79080-190 Campo Grande - MS Brasil ricadoaydos@gmail.com

Conflict of interest: none

Financial source: none
Received: Sep 19, 2016

Review: Nov 18, 2016

Accepted: Dez 20, 2016

${ }^{1}$ Research performed at Laboratory of Experimental Surgical Technique, Universidade Federal do Mato Grosso do Sul (UFMS), Campo Grande-MS, Brazil. Part of PhD degree thesis, Postgradu-ate Program in Health and Development. Tutor: Ricardo Dutra Aydos. 